\title{
A Novel Hexagonal Microstrip Antenna for UWB Applications
}

\author{
M.S. Angel Niharika \\ Master of Technology \\ Department of Electronics and Communication Engineering \\ Sri Venkateswara University College of Engineering, \\ Tirupati, India
}

\author{
Prof. G. Sreenivasulu \\ Professor, \\ Department of Electronics and Communication Engineering \\ Sri Venkateswara University College of Engineering, \\ Tirupati, India
}

\begin{abstract}
In this paper, a compact antenna comprised of hexagonal microstrip patch (MSPA) with slotted ground plane is proposed for ultra wideband applications. The radiating patch is in the hexagonal shape which is partially modified to obtain a flower structure. The antenna has compact size and is in the electrical dimension of $26 \times 24$ 】 $\mathrm{mm} \wedge 2$ with the substrate height of $1.6 \mathrm{mmfed}$ by $50 \Omega$ microstrip feed. The material used is FR4 epoxy substratewith relative permittivity 4.4 which is of low cost and has ease of fabrication. This method shows the improvement of proposed design performance in terms of bandwidth, size, gain and complexity. Proposed antenna has maximum gain of $9.4 \mathrm{dBi}$ for the radiating frequency band from $3.45-14.51 \mathrm{Ghz}$. The results are simulated using finite-element-method(FEM) based Ansoft HFSS software. The antenna has wide bandwidth which can be used in UWB radar,imaging and military applications.
\end{abstract}

Keywords-Hexagonal Patch, UWB, slotted ground, Microstrip feed.

\section{INTRODUCTION}

The important part in day to day's human life is communication whether it is for personal educational or business purpose. Wireless communications has become most efficient hassle-free and prominent means of information disseminating for communication these days. This is done through radio communication systems for interchange of information. For designing such efficient systems we need to have a device for receiving and radiating the information through radio waves which is called as antenna. An antenna is a transducer through which radio frequency energy is coupled from the transmitter and in reverse to the receiver via free space with air as a medium.. Antennas are used as an impedance transformer, impedance of free space and, coupling between an input or line impedance. Antenna is not only compact but is also non-dispersive and hence finds uses in many applications. Due to the prominent characteristics of Ultra wideband the UWB antennas became everyone,s intrest in the field of wireless communication. The microstrip patch antennas having very compact size and being able to be used at higher frequencies making them useful for high end applications such as defense, military, remote sensing etc. Hence, an efficient UWB antenna in all aspects is a somewhat critical part of the UWB system design.
For decades, UWB antennas are being used for active commercial purposes. For example, even a venerable AM broadcast antenna is "UWB" since it covers a band (5351705) $\mathrm{kHz}$. An AM broadcast antenna with higher quality is considered to be a tuned antenna that is designed to have individual narrowband channel of $10 \mathrm{kHz}$, the effective fractional $\mathrm{BW}$ is $0.6-1.9 \%$ and also, at a time only one channel is received. There is difficulty with UWB traditional antennas. They are not the antennas that are optimized for receiving single coherent signal along the entire bandwidth of operation, and are "multi-narrowband" antennas instead. Some of the modulation techniques can be more tolerant when it is regarding antenna variations. For example, OFDM approach or a multi-band is less vulnerable towards dispersion and others across the antenna's band of operation. Hence, an UWB system needs an antenna that is able to receive all frequencies same at a time. Thus, the behavior, performance, matching and pattern of an antenna must be predictable, consistent and stable across the band.

\section{RELATED WORK: EXISTING SYSTEM}

The IEEE 802.15 standard recognizes frequency ranges from 3.1 to $10.6 \mathrm{GHz}$ as UWB. UWB systems have been increasingly in demand for their low cost, low complexity, and high-data-rate. Demand for compact microstrip patch antennas is growing due to the small size \& large bandwidth[1]. In the beginning, the era of UWB systems, the UWB antennas were widely in use for high data rate applications. [2]-[3].It is yet quite difficult for designing a UWB antenna which is electrically small having high efficiency and reasonable gain [4]. Many microstrip patch antennas were reported mainly for UWB applications. Quite a few of these antennas are either large or do not cover the entire bandwidth. A tapered slot UWB antenna having an electrical dimension of $0.24 \mathrm{~mm} \times 0.22 \mathrm{~mm}$, e.g., covers the entire UWB band spectrum [1]. Referenced in [4], a heart-shaped monopole antenna has been mentioned to cover $2.70-26 \mathrm{GHz}$, but it uses the electrical dimension of $0.36 \mathrm{~mm} \times 0.43 \mathrm{~mm}$. A slot antenna with square ring used for imaging and radar applications [5] covers the UWB spectrum with a larger electrical dimension of $0.66 \mathrm{~mm} \times 0.66 \mathrm{~mm}$. Isik and Topaloglu [6] perform an experiment on a heart-shaped UWB antenna having triangular patches having an electrical dimension $0.33 \mathrm{~mm} \times 0.35 \mathrm{~mm}$, but it does not cover the lower band of 
the UWB. Heart-shaped antenna is presented which covers the BW from (2.1 to 11.5$) \mathrm{GHz}$ with the electrical dimension $(0.25 \mathrm{~mm} \times 0.21 \mathrm{~mm})$. A modified monopole semicircular antenna covers the UWB band spectrum, but it occupies a larger electrical dimension of $0.32 \mathrm{~mm} \times 0.25 \mathrm{~mm}$ [8]. A differential wide-slot UWB antenna with relatively larger electrical dimension of $0.28 \mathrm{~mm} \times 0.23 \mathrm{~mm}$ fails to cover the whole UWB spectrum [9].

In Existing system, the geometry of the brokenheart-shaped MSA. The antenna consists of patch brokenheart-shape with a slotted ground plane. The microstrip patch is printed with dimensions of $30 \mathrm{~mm} \times 20 \mathrm{~mm}$ onto one side of the substrate. The substrate has relative permittivity 4.6 with 0.02 loss tangent. The microstrip line having length $\mathrm{Lf}$, width $\mathrm{Wf}$ is printed on top of the substrate as the radiating component. The slotted ground plane is being printed onto the bottom of the substrate. A compact, slotted ground plane MSA with microstrip line is presented. The antenna achieves an impedance bandwidth of 2.90 to 10.70 $\mathrm{GHz}$ The antenna attains the maximum gain $5.3 \mathrm{dBi}$ and high efficiency of $86.6 \%$. The factors of fidelity for the side-by-side and face-to-face positions of the antenna are found to be $\sim 79 \%$ and $80 \%$, respectively.

\section{PROPOSED SYSTEM}

Hexagonal Microstrip antenna is becoming useful due to their light weight and low cost, they are most use microwave frequencies, and can be printed directly onto a circuit board. Generally, the most Microstrip patch antenna contains on surface, a 12a metal foil "patch" on top of the board, having a metal foil with a ground plane to the other side of the board, and also the patch is usually can be made by any achievable shape such as rectangular, square, elliptical, circular and hexagon. This method presented Hexagon shape antenna . Normally we always use inset feed and coaxial feed methods, because it is easy to realize and obtain input match. The hexagon patch antenna is a low profile antenna, because of it's structure, it has fair radiation ability, And the radiation is due to the open side edge of the patch. Here, the radiation patch length is almost half of its wavelength, where electric field is distributed in the same direction of horizontal component but is opposite in vertical component of open side.

$\mathrm{n}$ this method the antenna is designed using a hexagonal patch by printing it on dielectric substrate to obtain miniaturization, and hence the wideband characteristics using hexagon structure. Various techniques are implemented to achieve both. Here a hexagon shaped patch is used and a slotted groundplane is employed to obtain wideband behaviour whereas by employing a technique to get full groundplane by reducing the patch dimensions and narrowband characteristics of the antenna is realised.

The reason why we are using the radiator patch as hexagonal shape is because the performance characteristics (bandwidth) for a circular patch antenna is better in comparison with any other geometry. Circular patch geometry is nearly equal to that of hexagonal patch.
Recently for low-data-rate applications, like sensors, and radar communications, UWB systems are largely in use[2]. The asymmetric structure of patch and the offset feed line given from center of the substrate have a significant role in impedance matching[1]. The slot in groundplane have a vital role in increasing the impedance bandwidth due to electromagnetic coupling between the slotted ground plane and the radiating patch[6].

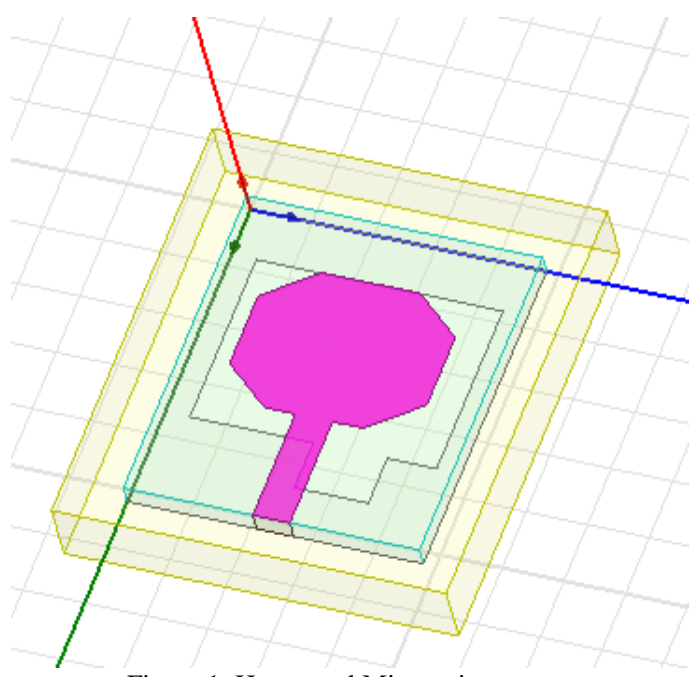

Figure 1: Hexagonal Microstrip antenna

The asymmetry of the patch structure with respect to thesubstrate forms the coupling between the patch and the ground. As a result, the lower resonance frequency moves into the lower band and the higher resonance frequency moves into the higher band, which enhances the impedance bandwidth. When the feed line is offset from the center of the substrate, it produces an impedance matching circuit. This circuit has negative capacitance, and hence the impedance becomes close to $50 \Omega$. For these asymmetric design properties, the presented antenna covers a wider bandwidth from 3 to more than $10.80 \mathrm{GHz}[1]$.

The feeding is done by using a microstrip feed where a conducting strip is directly attached to the microstrip patch and thereby producing a planar structure. The offset feed is given from the center of feedline to provide impedance matching and enhancing bandwidth of the antenna.

\section{ANTENNA DESIGN}

The proposed hexagonal microstrip patch antenna's geometry is as shown in the figure2. The microstrip patch antenna designed is operating at the frequency $6.54 \mathrm{Ghz}$ for a return loss as low as $-25 \mathrm{~dB}$. The antenna is produced using FR4 substrate having relative permittivity $\varepsilon r=4.4$. The substrate is compact with the dimensions $26 \times 24 \mathrm{~mm}^{2}$ and the height of the antenna is $h=1.6 \mathrm{~mm}$. The proposed antenna radiates in the frequency band $3.45 \mathrm{Ghz}-14.51 \mathrm{Ghz}$ which makes it flexible to use in UWB and very UWB applications. 


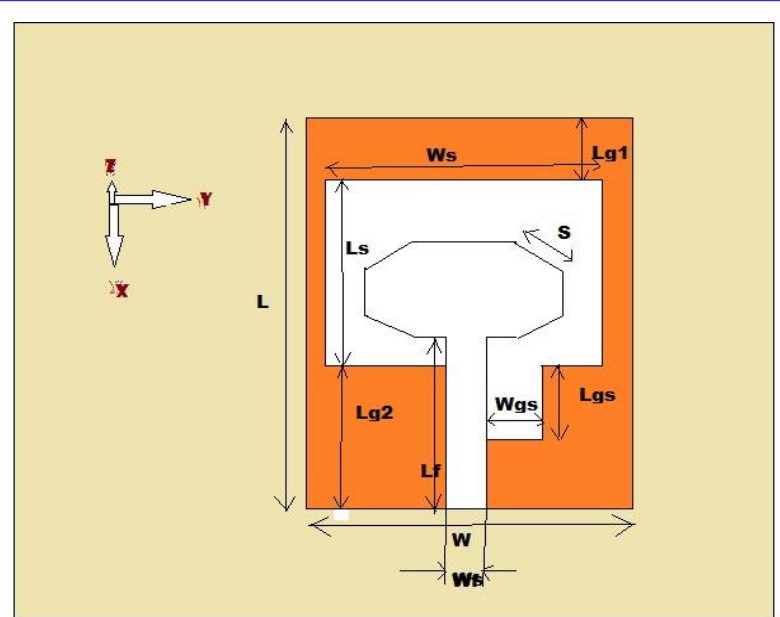

Figure 2: The geometry of the Proposed antenna

The parameters required for designing a microstrip patch antenna are calculated as below:

There are 3 main things to be considered while designing a MSPA namely resonant frequency (fo), thickness of dielectric material(h), and the relative permittivity of the substrate used for fabrication $\left(\varepsilon_{\mathrm{r}}\right)$. Based on these three, we will design the respective parameters of the proposed antenna.

\section{A. WIDTH OF THE PATCH}

The width of the patch antenna

$$
\mathrm{W}=\frac{C}{2 f_{r}} \sqrt{\frac{2}{\varepsilon_{r}+1}}
$$

Where,

$\mathrm{C}=$ velocity of light,

$\mathrm{f}_{\mathrm{r}}=$ resonant frequency

$\varepsilon_{\mathrm{r}}=$ dielectric constant of substrate

\section{B. EFFECTIVE REFRACTIVE INDEX}

The important parameter in the design of an microstrip antenna is its effective refractive index. The radiations travelling from both air and substrate have different values. So we go for effective refractive index and it is calculated as, For $\frac{W}{h}>1$

$\varepsilon_{\text {reff }}=\frac{\varepsilon_{r}+1}{2}+\frac{\varepsilon_{r}-1}{2}\left(\frac{1}{\sqrt{1+\frac{12 h}{W}}}\right)$

Where,

$\mathrm{h}$ is the thickness of the substrate

$\mathrm{W}$ is the wisth of the patch

\section{LENGTH OF THE PATCH}

The size of the antenna is varied due to the fringing by a small amount $\Delta L$. So the length of the patch is comprised of effective length and the change in length due to fringing effect, which is given as

$$
\mathrm{L}=\mathrm{L}_{\text {eff }}-2 \Delta L
$$

$\mathrm{L}_{\text {effis given as, }}$

$$
\mathbf{L}_{\text {eff }}=\frac{\lambda g}{2}=\frac{C}{2 f_{r} \sqrt{\varepsilon_{r e f f}}}
$$

$\lambda_{g}$ is the guided wavelength

And the change in length $\Delta L$, is given as,

$$
\frac{\Delta L}{h}=0.412 \times \frac{\left(\boldsymbol{\varepsilon}_{\text {reff }}+0.3\right)\left(\frac{W}{h}+0.264\right)}{\left(\boldsymbol{\varepsilon}_{\boldsymbol{r e f f}}-0.258\right)\left(\frac{W}{h}+0.8\right)}(5)
$$

\section{LENGTH $\left(\mathrm{L}_{\mathrm{g}}\right) \mathrm{WIDTH}\left(\mathrm{W}_{\mathrm{g}}\right)$ OF GROUND PLANE}

The length and width of the ground plane are same as that of the substrate and are given as,

$$
\begin{aligned}
& \mathrm{L}_{\mathrm{g}}=6 \mathrm{~h}+\mathrm{L} \\
& \mathrm{W}_{\mathrm{g}}=6 \mathrm{~h}+\mathrm{W}
\end{aligned}
$$

The final parameters of the proposed antenna are given asL $=26 \mathrm{~mm}, \mathrm{~W}=24 \mathrm{~mm}, \mathrm{~L}_{\mathrm{g} 1}=6 \mathrm{~mm}, \mathrm{Lg}_{2}=10 \mathrm{~mm}$, $\mathrm{L}_{\mathrm{S}}=10 \mathrm{~mm}, \mathrm{~S}=3 \mathrm{~mm}, \mathrm{~L}_{\mathrm{f}}=13 \mathrm{~mm}, \mathrm{~W}_{\mathrm{f}}=6 \mathrm{~mm}, \mathrm{~L}_{\mathrm{gs}}=$ $7 \mathrm{~mm}, \mathrm{~W}_{\mathrm{gs}}=5 \mathrm{~mm}$ and $\mathrm{h}=1.6 \mathrm{~mm}$.

\section{RESULTS}

\section{Simulation Results}

HFSS is a widely used software tool to design an antenna, for modeling its antenna structure. HFSS stands for High Frequency Structure Simulator. Ansoft Corporation uses HFSS as a propriety software. The parameters of the antenna design are obtained from the available equations. After calculating the antenna parameters, a model is generated in HFSS. Now, to plot the radiation pattern, Radiation box is allocated. Now, the simulation process will start and we will obtain results from the given parameters for the proposed antenna.

\section{Return Loss}

Return loss indicates how much power that is "lost" to the load which does not reflect back. So, it is a constraint that indicates how well there is matching between antenna and the transmitter. The bandwidth is calculated based on values from return loss (RL) plot. The given antenna bandwidth can be observed as the band of frequencies over which the return losses are less than $-10 \mathrm{~dB}$. When we observe the figure, resonance frequency of this antenna ia at $6.54 \mathrm{Ghz}$ and by using the desired equation for calculating $\mathrm{RL}$, the generated antenna bandwidth is observed to be more than $50 \%$. Thus, the proposed antenna is studied as an ultra wide band. 


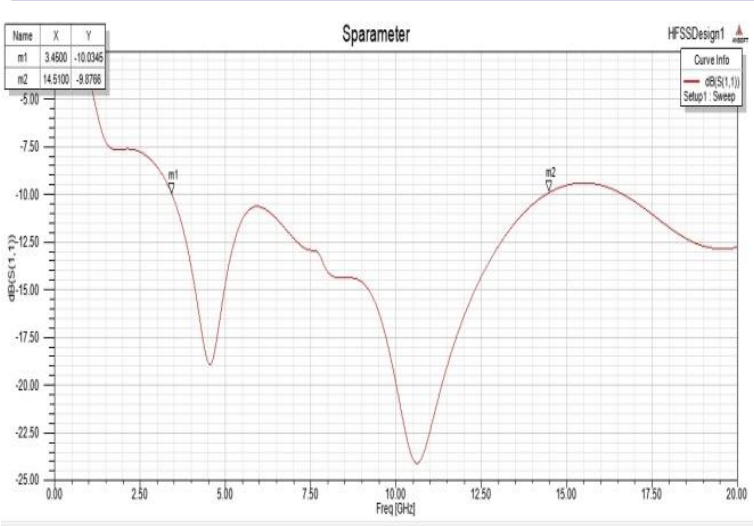

Figure 3: Return loss[S11] of the presented antenna

\section{VSWR (VOLTAGE STANDING WAVE RATIO)}

Voltage Standing Wave Ratio (VSWR) is a quality metric for the impedance matching. VSWR is usually abbreviated as SWR. High VSWR indicates reflection of the signal before it is radiated from the antenna. VSWR and and the power reflected are variant ways to express and measure the same thing

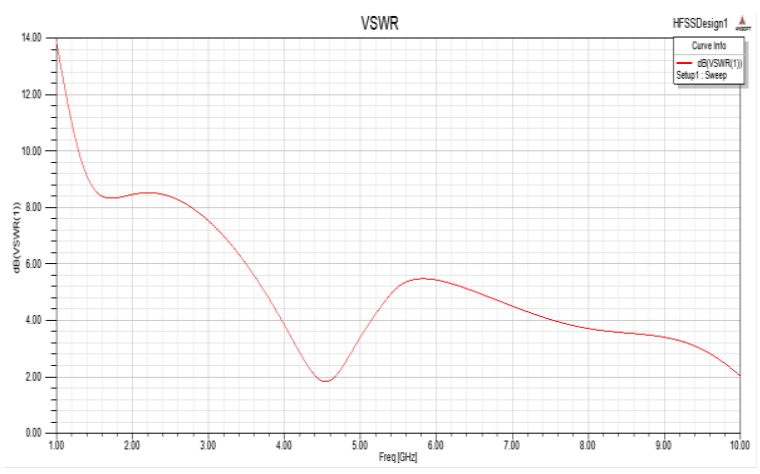

Figure 4:VSWR of the presented antenna

When the condition of matching is not satisfied, that means, $\mathrm{ZL}=\mathrm{Z} 0$, then the power may be reflected back which leads to the creation of standing waves. VSWR is used to categorize the parameters of the standing waves . Voltage standing wave ratio(VSWR) is used to express the degree of match between the antenna and the transmission line. If the VSWR is $1: 1$, it is perfectly matched and all the energy is being transferred to the antenna prior to be radiated. In addition, for an antenna to be reasonably functional, a maximum value of VSWR.

\section{Radiation Pattern}

The performance of a linearly polarized antenna is usually analyzed on the basis of its Principal E- and H-plane patterns. The antenna radiation pattern is a plot having properties of the far- field which is a function of spatial coordinates that are specified by the azimuth $(\varphi)$ and the elevation angle $(\theta)$.
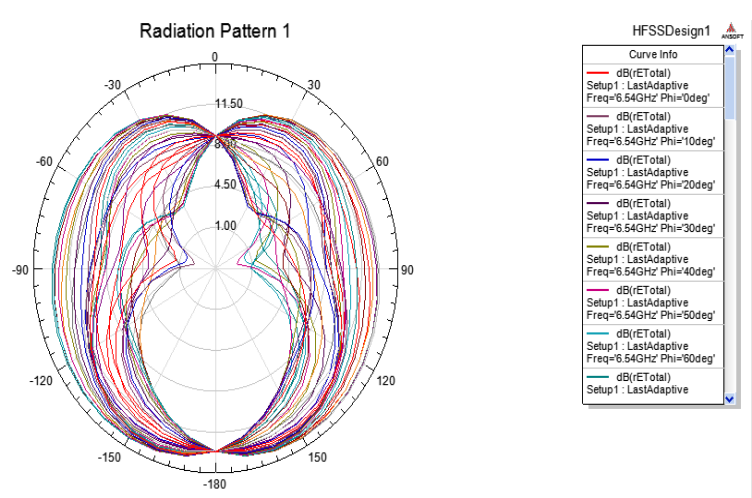

Figure 5: Radiation pattern of the presented antenna at $6.54 \mathrm{Ghz}$

\section{Directivity and Gain}

Antenna directivity is described as "the ratio of the averaged radiation intensity over all the directions to the radiation intensity from the antenna in a given direction. The average radiation intensity is equal to the total power radiated by the antenna divide by $4 \prod$. Antenna gain is the relative measure of an antenna's ability to concentrate RF (radio frequency) or to direct energy in a specific pattern or direction. Typically measured in decibels related to the dipole radiator $(\mathrm{dBd})$ or decibels related to the isotropic radiator $(\mathrm{dBi})$.
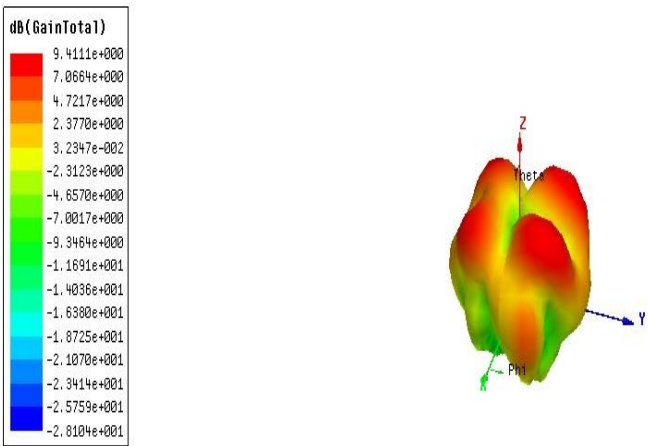

Figure 6:Gain

Table 1: Comparision of parameters

\begin{tabular}{|l|l|l|}
\hline Parameters & $\begin{array}{l}\text { Existing } \\
\text { Method }\end{array}$ & $\begin{array}{l}\text { Proposed } \\
\text { Method }\end{array}$ \\
\hline $\begin{array}{l}\text { Radiating } \\
\text { Frequency Band } \\
\text { (Ghz) }\end{array}$ & $\begin{array}{l}2.02- \\
10.02\end{array}$ \\
\hline Gain(dB) & 5.7 & $3.45-14.51$ \\
\hline VSWR & 1.01 & 9.4 \\
\hline Bandwidth(Ghz) & 6.74 & 1.71 \\
\hline Size $\left(m m^{2}\right)$ & $30 \times 20.5$ & 7.90 \\
\hline Efficiency(\%) & 86.6 & $26 \times 24$ \\
\hline Impedance $(\Omega)$ & 50 & 89.7 \\
\hline
\end{tabular}




\section{CONCLUSION}

The proposed hexagonal microstrip antenna has been proposed for UWB communication systems. It has been presented by simulated results that the gain of this antenna is much better than the existing system. A further improvement in the modified antenna can be done to provide approximately at the stop band to increase the frequency range to avoid interference from WLAN .

\section{REFERENCES}

[1] N. Rahman, M. T. Islam, Z. Mahmud, M. Samsuzzaman, “ The Broken-Heart Printed Antenna for Ultra-wideband Applications: Design and Characteristics Analysis," IEEE Antennas and Propagation Magazine, vol. 60, no. 6, pp. 45-51, Dec 2018.

[2] S. Singhal and A. K. Singh, "CPW-fed hexagonal Sierpinski super wideband fractal antenna," IET Microw. Antennas Propag., vol. 10, no. 15 , pp. $1701-1707,2016$.

[3] R. Azim, M. T. Islam, and N. Misran, "Compact tapered-shape slot antenna for UWB applications," IEEE Antennas Wireless Propag. Lett., vol. 10, pp. 1190-1193, 2011.

[4] M. Schmidt, D. Simic, and R. Moorfeld, "Low complexity low data rate UWB devices-Architecture and performance comparison," presented at the IST Mobile \& Wireless Communications Summit, 2005.

[5] M. Z. Win, D. Dardari, A. Molisch, W. Wiesbeck, and J. Zhang, "History and applications of UWB," Proc. IEEE, vol. 97, no. 2, pp. 198-204. Feb. 2009.

[6] C. F. Torres, J. M. Monroy, H. L. Morales, R. C. Pérez, and A. C. Tellez, "Heart shaped monopole antenna with defected ground plane for UWB applications," in Proc. 2014 11th Int. Conf. Electrical Engineering, Computing Science and Automatic Control (CCE), pp. $1-4$.

[7] R. R. Krishna and R. Kumar, "A dual-polarized square-ring slot antenna for UWB, imaging, and radar applications," IEEE Antennas Wireless Propag. Lett., vol. 15, pp. 195-198, June 2016.

[8] G. Isik and S. Topaloglu, "A compact size 4-19.1 GHz heart shape UWB antenna with triangular patches," Int. J. Antennas Propagation, vol. 2013, 2013. doi: 10.1155/2013/614754.

[9] T. Yang and X. J. Tian, "A novel heart shaped monopole antenna for UWB and RFID applications,” Microw. Opt. Technol. Lett., vol. 53, no. 10 , pp. 2288-2291, Oct. 2011.

[10]A. M. Abdelraheem and M. A. Abdalla, "Compact curved half circular discmonopole UWB antenna," Int. J. Microw Wireless Technol., vol. 8, no. 2, pp. 283-290, 2016.

[11]Z.-H. Tu, Y.-Y. Liu, and Q.-X. Chu, "Differential wide-slot UWB antenna with band-notched applications," in Proc. 2016 IEEE Int. Conf. Computational Electromagnetics (ICCEM), pp. 265-267.

[12] N. A. Murugan, R. Balasubramanian, and H. R. Patnam, "Printed ultrawideband monopole U-slotted antenna for triple band-rejection," J. Electromagn. Waves Applicat., vol. 30, no. 12, pp. 1532-1544, 2016.

[13]Manohar, M., Kshetrimayum, R.S., Gogoi, A.K.: 'Printed monopole antenna with tapered feedline, feed region and patch for super wideband applications', IET Microw. Antennas Propag., 2014, 8, (1), pp. $39-45$

[14]Balanis, C.A., Antenna Theory: 'Analysis and design' (3rd edn., Hoboken, NJ: John Wiley, 2005). 